J. Perinat. Med. 16 (1988) 299

\section{The first derivative as a means of synchronizing pulsatile flow velocity and vessel diameter waveforms in the fetal descending aorta}

\author{
Hilda Margaret Tonge ${ }^{1}$, Peter Cornelis Struijk ${ }^{2}$, Cornelis van Kooten ${ }^{2}$, Juriy Wybe \\ Wladimiroff ${ }^{1}$, and Nicolas Bom ${ }^{3}$ \\ ${ }^{1}$ Department of Obstetrics and Gynecology, ${ }^{2}$ Central Research Laboratory, and \\ ${ }^{3}$ Department of Cardiovascular Research, Erasmus University, Rotterdam, The \\ Netherlands
}

\section{Introduction}

It has become increasingly clear that measurements of blood flow velocity and in particular the vessel diameter for estimating volume flow in the fetal descending aorta, are subject to a number of inaccuracies $[1,6]$.

One of the important factors in the study of arterial volume flow is the pulsatility of both the flow velocity and vessel diameter profiles. Simultaneous recording of these profiles would allow the construction of a volume flow waveform which takes the pulsatile character of the vessel diameter into account. This is impossible due to unacceptable interference between emitted pulses from realtime and Doppler transducers. An indirect solution to the problem is to compare blood flow velocity and pulsatile vessel diameter prifiles in cardiac cycles of similar length as determined by the fetal ECG $[3,5]$.

An optimal fetal ECG recording cannot always be obtained, even with present day fetal heart rate monitors. Accordingly, we looked for an alternative method of synchronizing pulsatile blood flow velocity and vessel diameter waveforms in the fetal descending aorta that was not dependent on obtaining a fetal ECG. The onset of both waveforms is almost simultaneous [3]. This information was applied to synchronize the two waveforms. To determine the onset of the cardiac cycles the first derivative of the blood flow velocity and pulsatile vessel diameter waveforms was used.

This paper presents (i) a comparative study, where volume blood flow data obtained from the lower thoracic level of the fetal descending aorta was analyzed initially by the original fetal ECG method [5], and, secondly, re-analyzed using the alternative method in which the first derivative is used for synchronization; (ii) preliminary data on volume flow in the fetal descending aorta in normal third trimester pregnancies using the first derivative method.

\section{Material and methods}

The comparative study was performed in a fetal lamb at 130 days $(0.9)$ of gestation in the first instance. After induction of anesthesia with ketamine hydrochloride $(1000 \mathrm{mg})$, atropine $(0.5 \mathrm{mg})$ and pentobarbital sodium $(300 \mathrm{mg})$ intravenously, the ewe was intubated. An abdominal midline incision was made and the pregnant uterus was subsequently exposed. Throughout surgery the ewe was ventilated with a mixture of nitrous oxide $(4: 1)$ and oxygen $(2: 1)$ supplemented by enflurane $(0.5-2$ vol\%).

In the second instance, the study was performed in a normal, non smoking human gravida of 37 weeks gestation $(0.9)$, in a semi-recumbent position.

In both the fetal lamb and human fetus, the following three physiological signals were obtained:

- the pulsatile blood flow velocity waveform in the fetal descending aorta using a $2 \mathrm{MHz}$ pulsed Doppler system (PEDOF) attached to a $3.12 \mathrm{MHz}$ linear array real-time transducer (Organon Teknika). In the fetal lamb the realtime transducer was placed directly on the uterine wall. 
- the pulsatile vessel diameter waveform in the fetal descending aorta using a dual time-distance (TD) recorder. From the real-time image (Organon-Teknika) a line was selected and the markers of the TD recorder were positioned on the deflections of the A-mode representation of the proximal and distal vessel wall.

- the fetal ECG by means of an abdominal ECG monitor (HP-8040). From the maternal abdominal wall in the human study and from electrodes placed in the fetal hind legs in the lamb study. In the analogue output of the ECG monitor a block-shaped pulse indicated the R-top of the fetal ECG.

An Apple II microcomputer was used for data collection following analgue/digital conversion (AI 13, Interactive Structures Inc). All analogue signals were sampled for a fixed period of five seconds at a frequency of $200 \mathrm{~Hz}$, resulting in 1000

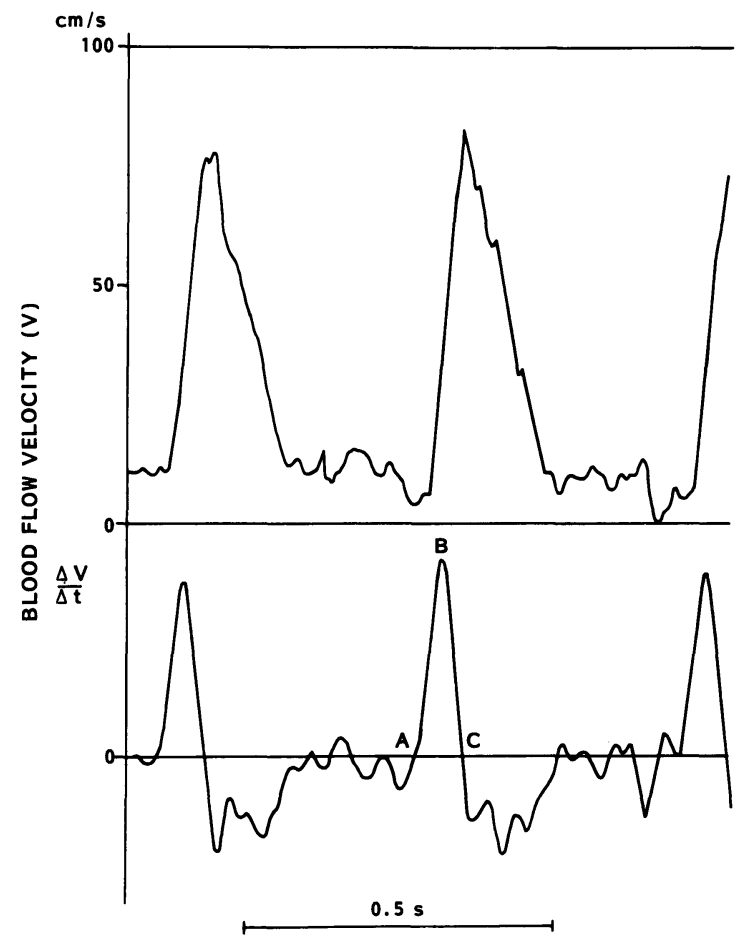

Figure 1. First derivative of the blood flow velocity waveform. $\mathrm{A}=$ onset of cardiac cycle; $\mathrm{B}=$ point of maximum rise in the waveform; $\mathrm{C}=$ peak velocity. samples for each signal and thus allowing a detailed description of each signal (figures 1 and 2). In the first derivative method, a rise in the upstroke of $750\left(\mathrm{~cm} \mathrm{~s}^{-2}\right)$ for the blood flow velocity profile and of $6 \mathrm{~mm} \mathrm{~s}^{-1}$ for the pulsatile vessel diameter profile was arbitrarily selected for accepting a particular cardiac cycle (figures 1 and 2). The maximum rate of rise of the blood flow velocity and pulsatile vessel diameter waveforms was calculated as the peak (B) in the first derivative.

The zero-line crossing (A) preceding this peak was defined as the onset, the zero-line crossing (C) following the peak as the location of the peak in the original blood flow velocity and pulsatile vessel diameter waveforms.

Initially, matching of the blood flow velocity and pulsatile diameter waveforms was carried-out using the R-R intervals of the fetal ECG. A difference in cardiac cycle length of $5 \%$ was the maxi-

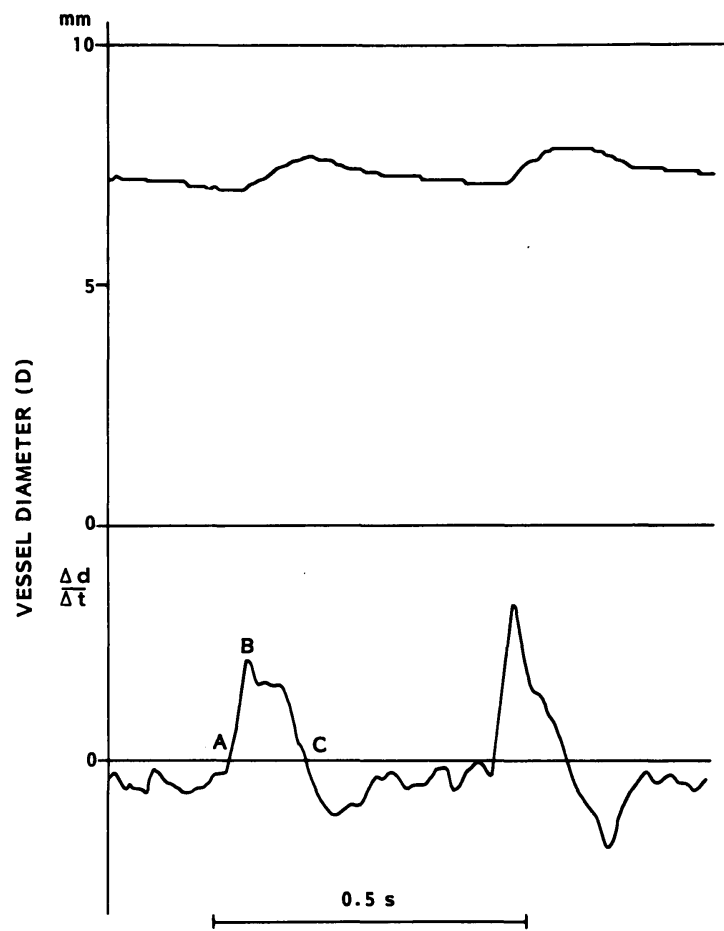

Figure 2. First derivative of the pulsatile vessel diameter waveform. $\mathrm{A}=$ onset of cardiac cycle; $\mathrm{B}=$ point of maximum rate of rise of the waveform; $\mathrm{C}=$ maximum diameter. 
mum tolerated discrepancy permitted for synchronization of the two waveforms. The following parameters were calculated:

a. the pulsatile flow velocity waveform: lagtime between R-top fetal ECG and onset flow felocity (ms), period time (ms), crest time (ms) $=$ time interval between onset and peak velocity, velocity acceleration $\left(\mathrm{cm} \mathrm{s}^{-2}\right)$, peak and end-diastolic velocities $\left(\mathrm{cm} \mathrm{s}^{-1}\right)$, averaged velocity $\left(\mathrm{cm} \mathrm{s}^{-1}\right)$ and pulsatility index [2].

b. the pulsatile vessel diameter waveform: lagtime between R-top fetal ECG and onset diameter waveform (ms), period time (ms), crest time (ms), expansion velocity $\left(\mathrm{mm} \mathrm{s}^{-1}\right)$, maximum and minimum diameters ( $\mathrm{mm})$ and averaged diameter $(\mathrm{mm})$.

c. the volume flow profile: peak flow $\left(\mathrm{ml} \mathrm{min}^{-1}\right)$, aortic stroke volume $(\mathrm{ml})$, averaged volume flow $\left(\mathrm{ml} \mathrm{min}^{-1}\right)$.
In the fetal lamb, a total of 33 cardiac cycles was matched. In the human fetus, the total was 10 .

Having completed analysis using the fetal ECG, cardiac cycles were resynchronized applying the first derivative method. The cardiac cycles were matching using onset-to-onset intervals, and the same parameters were calculated. For the fetal lamb, the selected velocity cycles were the same as those utilized for the fetal ECG matching. The computer selected, however, only 25 of the same diameter cycles that were utilized in the fetal ECG synchronization. Similarly, for the human fetus, the velocity cycles were the same. The computer selected only 5 of the same diameter cycles that were utilized for the fetal ECG matching. The diameter cycles used for the first derivative synchronization only were those cardiac cycles that were found to fit the criterium described earlier, where there was a $5 \%$ or less difference in cardiac cycle length.

Table I. Blood flow velocity, pulsatile vessel diameter and volume flow data at the lower thoracic level fo the fetal descending aorta according to fetal ECG (FECG) and first derivative synchronized cardiac cycles in the fetal lamb

\begin{tabular}{|c|c|c|c|c|c|}
\hline & \multicolumn{2}{|c|}{ According to FECG } & \multicolumn{2}{|c|}{$\begin{array}{l}\text { According to first } \\
\text { derivative method }\end{array}$} & \multirow[t]{2}{*}{$\%$ Difference } \\
\hline & $\mathbf{X}$ & SD & $\bar{X}$ & SD & \\
\hline \multicolumn{6}{|l|}{ Velocity cycles } \\
\hline Lagtime R-top FECG/onset FVWF (ms) & 54 & 9 & - & - & - \\
\hline Crest time (ms) & 84 & 12.5 & 84 & 12.5 & 0.0 \\
\hline Period time (ms) & 308 & 25 & 305 & 24 & -1.0 \\
\hline Peak velocity $\left(\mathrm{cm} \mathrm{s}^{-1}\right)$ & 55.7 & 9.9 & 55.7 & 9.9 & 0.0 \\
\hline End diastolic velocity $\left(\mathrm{cm}^{-1}\right)$ & 9.4 & 3.8 & 3.9 & 9.8 & -58.5 \\
\hline Averaged velocity $\left(\mathrm{cm} \mathrm{s}^{-1}\right)$ & 23.7 & 6.8 & 23.6 & 7.0 & -0.4 \\
\hline Pulsality index & 2.0 & 0.3 & 2.4 & 0.8 & 20.0 \\
\hline Velocity acceleration $\left(\mathrm{cm} \mathrm{s}^{-2}\right)$ & 1112 & 170 & 1112 & 170 & 0.0 \\
\hline \multicolumn{6}{|l|}{ Diameter cycles } \\
\hline Lagtime R-top FECG/onset VDWF (ms) & 50 & 24 & - & - & - \\
\hline Crest time (ms) & 113 & 22 & 116 & 18 & -2.7 \\
\hline Period time (ms) & 300 & 30 & 309 & 27 & 3.0 \\
\hline Maximum diameter (mm) & 7.5 & 0.4 & 7.5 & 0.4 & 0.0 \\
\hline Minimum diameter (mm) & 7.2 & 0.5 & 6.7 & 0.4 & -6.9 \\
\hline Averaged diameter (mm) & 7.3 & 0.4 & 7.2 & 0.4 & -1.4 \\
\hline Expansion velocity $\left(\mathrm{cm} \mathrm{s}^{-1}\right)$ & 8.9 & 2.3 & 8.8 & 2.4 & -1.1 \\
\hline \multicolumn{6}{|l|}{ Calculated volume flow cycles } \\
\hline Averaged flow $(\mathrm{ml} \mathrm{min}-1)$ & 581 & 110 & 575 & 117 & -1.0 \\
\hline Aortic stroke volume $(\mathrm{ml})$ & 2.9 & 0.4 & 2.9 & 0.4 & 0.0 \\
\hline Peak flow $\left(\mathrm{ml} \mathrm{min}^{-1}\right)$ & 1439 & 130 & 1431 & 139 & -0.6 \\
\hline
\end{tabular}

FVWF $=$ flow velocity waveform; VDWF $=$ vessel diameter waveform. 
A total of 18 patients with normal singleton pregnancies between 30 and 41 weeks of gestation consented to participate in the study. The gestational age had been calculated from a reliable menstrual history and early ultrasonic measurement of fetal crown-rump length or biparietal diameter. Nine patients were between 30 and 35 weeks gestation, and nine patients were between 36 and 41 weeks gestation.

Statistical analysis was performed using the paired student's t-test.

\section{Results}

Tables I and II present the data on blood flow velocity, pulsatile vessel diameter and volume flow (mean \pm SD) calculated from the waveforms in the fetal lamb and human fetus. According to the fetal ECG synchronization, for the fetal lamb, the lagtime between the R-top fetal ECG and the onset of the blood flow velocity cardiac cycles was
$54 \mathrm{~ms}$; whereas, the lagtime between the R-top fetal ECG and the onset of the pulsatile vessel diameter cardiac cycles was $50 \mathrm{~ms}$. This is a difference of $-4 \pm 29$ (SD) ms. Likewise, for the human fetus, this difference was $+6 \pm 13$ (SD) $\mathrm{ms}$. These differences are not statistically significant.

The percentage differences in end-diastolic velocities for the fetal lamb and human fetus between the first derivative synchronization and fetal ECG synchronization were -58.5 and -53.1 respectively. These are statistically significant values $(\mathrm{p}<0.01)$. The pulsatility index value was therefore significantly higher in the fetal ECG cardiac cycles $(p<0.01)$. The percentage differences in minimum diameter for the fetal lamb and human fetus between both methods of matching were also statistically significant $(\mathrm{p}<0.01)$. There was no statistically significant difference found for any of the other parameters, including volume flow calculations.

Table II. Blood flow velocity, pulsatile vessel diameter and volume flow data at the lower thoracic level of the fetal descending aorta according to fetal ECG (FECG) and first derivative synchronized cardiac cycles in the human fetus

\begin{tabular}{|c|c|c|c|c|c|}
\hline & \multicolumn{2}{|c|}{ According to FECG } & \multicolumn{2}{|c|}{$\begin{array}{l}\text { According to first } \\
\text { derivative method }\end{array}$} & \multirow[t]{2}{*}{$\%$ Difference } \\
\hline & $\mathrm{X}$ & SD & $\mathrm{X}$ & SD & \\
\hline \multicolumn{6}{|l|}{ Velocity cycles } \\
\hline Lagtime R-top FECG/onset FVWF (ms) & 46 & 12 & - & - & - \\
\hline Crest time $(\mathrm{ms})$ & 85 & 15 & 85 & 15 & 0.0 \\
\hline Period time (ms) & 431 & 7 & 432 & 17 & 0.2 \\
\hline Peak velocity $\left(\mathrm{cm} \mathrm{s}^{-1}\right)$ & 73.1 & 3.7 & 73.1 & 3.7 & 0.0 \\
\hline End diastolic velocity $\left(\mathrm{cm}^{-1}\right)$ & 9.6 & 2.3 & 4.5 & 2.1 & -53.1 \\
\hline Averaged velocity $\left(\mathrm{cm} \mathrm{s}^{-1}\right)$ & 24.2 & 2.4 & 24.1 & 2.5 & -0.4 \\
\hline Pulsatility index & 2.6 & 0.2 & 2.9 & 0.3 & 11.5 \\
\hline Velocity acceleration $\left(\mathrm{cm} \mathrm{s}^{-2}\right)$ & 1673 & 194 & 1673 & 194 & 0.0 \\
\hline \multicolumn{6}{|l|}{ Diameter cycles } \\
\hline Lagtime R-top FECG/onset VDWF (ms) & 52 & 6 & - & - & - \\
\hline Crest time (ms) & 118 & 12 & 125 & 11 & 5.9 \\
\hline Period time (ms) & 431 & 7.4 & 437 & 13 & 1.4 \\
\hline Maximum diameter $(\mathrm{mm})$ & 8 & 0.5 & 8.1 & 0.6 & 1.3 \\
\hline Minimum diameter (mm) & 7.6 & 0.5 & 7.4 & 0.5 & -2.6 \\
\hline Averaged diameter (mm) & 7.8 & 0.5 & 7.7 & 0.5 & -1.3 \\
\hline Expansion velocity $\left(\mathrm{cm} \mathrm{s}^{-1}\right)$ & 9.7 & 2.1 & 8.9 & 0.6 & -8.2 \\
\hline \multicolumn{6}{|l|}{ Calculated volume flow cycles } \\
\hline Averaged flow $\left(\mathrm{ml} \mathrm{min}^{-1}\right)$ & 729 & 143 & 701 & 130 & -3.7 \\
\hline Aortic stroke volume (ml) & 5.2 & 1.0 & 5.1 & 1.0 & -1.9 \\
\hline Peak flow $\left(\mathrm{ml} \mathrm{min}^{-1}\right)$ & 2254 & 315 & 2196 & 327 & -2.6 \\
\hline
\end{tabular}

$\mathrm{FVWF}=$ flow velocity waveform; VDWF $=$ vessel diameter waveform. 
In the preliminary clinical study averaged mean blood flow ( $\mathrm{ml} / \mathrm{min}$ ) was $396.4 \pm 60.0$ (SD) between 30 and 35 weeks and $618.9 \pm 76.0$ (SD) between 36 and 41 weeks. This difference was statistically significant $(\mathrm{p}<0.0005)$.

\section{Discussion}

The present study shows a good agreement between fetal ECG and "first derivative" synchronized cardiac cycles with respect to nearly all blood flow velocity and pulsatile vessel diameter parameters both in the fetal lamb and human fetus.

Both in the fetal lamb and human fetus, the mean time lag between the onset of the blood flow velocity and pulsatile vessel diameter waveforms appeared to be negligible ( 4 and $6 \mathrm{msec}$ ), so that the onset of both waveforms can be considered as being simultaneous. This is in agreement with other studies $[3,4]$. The significant difference in end-diastolic flow velocity and minimum vessel diameter between the two methods of synchronization is determined by artificially increased enddiastolic flow velocity and minimum vessel diameter values using the fetal ECG. This is due to the lagtime between the R-top of the fetal ECG and onset of both waveforms (figure 3). In other words, the cardiac cycles of the fetal ECG precede the cardiac cycles of the blood flow velocity and pulsatile vessel diameter waveforms (figure 3). It can be concluded that the first derivative method is a satisfactory replacement to the fetal ECG as a means of synchronizing blood flow velocity and pulsatile vessel diameter waveforms in the fetal descending aorta. Its easy applicability offers an attractive alternative to the fetal ECG. It will serve as a useful tool on further comparative studies on pulsatile changes in human fetal aortic flow velocity and vessel diameter waveforms both under physiological and pathophysiological circumstances.

\section{Abstract}

In order to calculate volume flow, blood flow velocity and pulsatile vessel diameter waveforms in the lower thoracic part of the descending aorta of the fetal lamb and human fetus were matched for indentical cardiac cycle length by fetal ECG and the first derivative of these waveforms. Volume flow values were not essen-
}

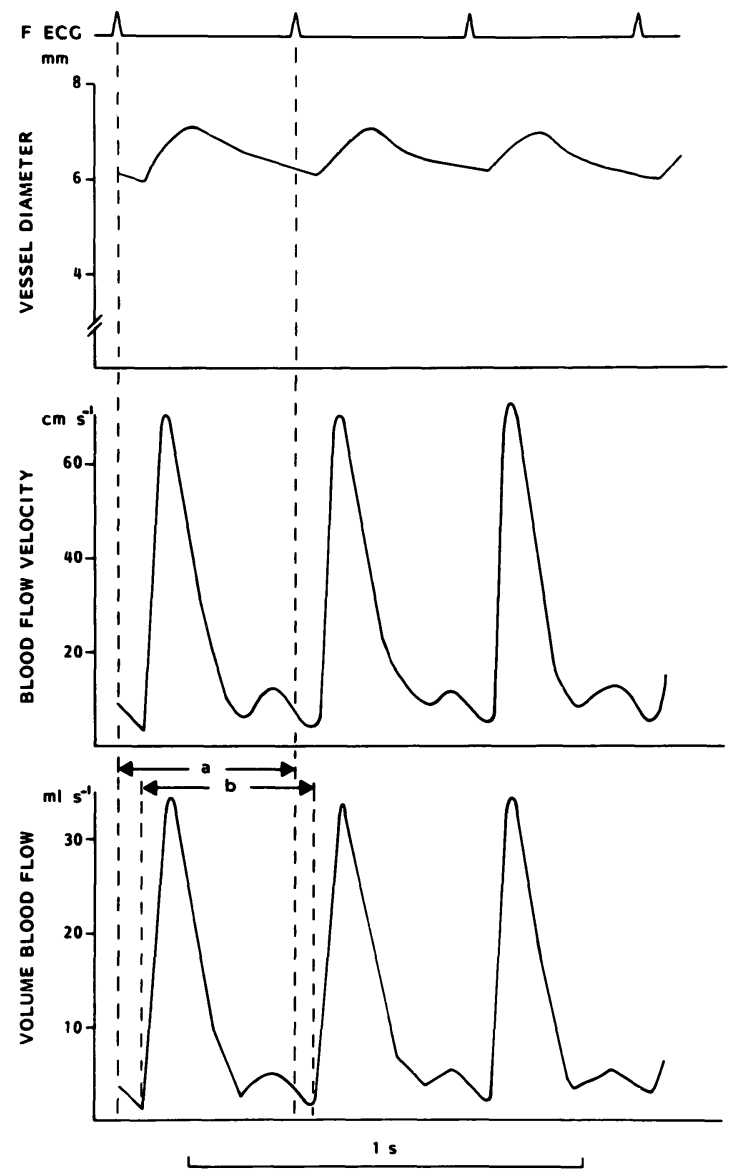

Figure 3. The synchronization of the pulsatile vessel diameter and blood flow velocity waveforms by fetal ECG, from which volume blood flow waveforms can be constructed. $(a-b)=$ lagtime between fetal ECG and onset of the cardiac cycles for all waveforms.

Keywords: Aortic diameter, aortic flow velocity, fetal blood flow, pulsed Doppler. 


\section{Zusammenfassung}

Die erste Ableitung der pulsatilen Flußkurve der Aorta des. als Mittel zur Synchronisation der Geschwindigkeitsund der Gefäßdurchmesserkurve

Um das Flußvolumen, die Blutflußgeschwindigkeit und den pulsierenden Gefäßdurchmesser im unteren Thoraxanteil der Aorta des. im Lammfeten und im menschlichen Feten berechnen zu können, wurden über das fetale EKG die Pulse zu gleichen Herzzyklen bestimmt und die zugehörigen ersten Ableitungen dieser Wellenformen gebildet. Der Beginn der Blutflußgeschwindigkeit und der des pulsatilen Gefäßdurchmessers ist gleich. Die erste Ableitung kann zuverlässig das fetale EKG als Mittel zur Synchronisation der Wellen der Flußgeschwindigkeit und des pulsierenden Gefäßdurchmessers in der fetalen Aorta des. ersetzen.

Schlüsselwörter: Aortendurchmesser, fetaler Blutfluß, Flußgeschwindigkeit in der Aorta, gepulster Doppler.

\section{Résumé}

La première dérivée: moyen de synchronisation de la vélocité du flux sanguin et des ondes pulsatiles du diamètre des vaisseaux au niveau de l'aorte descendante du foetus Afin de calculer le débit, la vélocité du flux sanguin et les ondes pulsatiles du diamètre des vaisseaux au niveau de la portion thoracique inférieure de l'aorte descendante du fœtus d'agneau et du fotus humain, ont été appariées quant à la longueur identique du cycle cardiaque sur l'ECG fœtal et la première dérivée de ces ondes. Les valeurs du débit ne sont pas notablement différentes quelle que soit la méthode. La vélocité du flux sanguin et les ondes pulsatiles du diamètre des vaisseaux débutent simultanément. La première dérivée peut remplacer de façon fiable l'ECG fotal comme moyen de synchronisation de la vélocité du flux sanguin et des ondes pulsatiles du diamètre des vaisseaux au niveau de l'aorte fœtale descendante.

Mots-clés: Débit sanguin fœtal, diamètre aortique, doppler pulsé, vélocité du flux aortique.

\section{References}

[1] Eik-Nes SH, K Marsál, AO BrubaKK, K KrisTOFFERSEN, M ULSTEIN: Ultrasonic measurement of human fetal blood flow. J Biomed Eng 4 (1982) 28

[2] GosLing RG, DH KING: Ultrasound Angiology. In: Marcus AW, L ADAmson (eds): Arteries and Veins, p. 61. Churchill Livingstone, Edinburgh 1975

[3] Lingman G, G Gennser, K Marsál: Ultrasonic measurements of the blood velocity and pulsatile diameter changes in the fetal descending aorta. In: Rolfe P (ed): Fetal and Neonatal Physiological Measurements. Butterworths, Tunbridge (in press)

[4] Lingman G, K Marsál: Fetal central blood circulation in the third trimester of normal pregnancy. A longitudinal study. II. Aortic blood velocity waveform. Early Hum Dev 13 (1986) 151
[5] Tonge HM, PC Struijk, P Custers, JW WladiMIROFF: Vascular dynamics in the descending aorta of the human fetus in normal late pregnancy. Early Hum Dev 9 (1983) 21

[6] Tonge HM, PC StruIJK, JW WLAdimiRoff: Blood flow measurements in the fetal descending aorta; Technique and clinics. Clin Cardiol 7 (1984) 323

J. W. Wladimiroff, M.D., Ph. D.

Professor of Obstetrics \& Gynecology

Academic Hospital Rotterdam-Dijkzigt

Erasmus University Rotterdam

Dr. Molewaterplein 40

NL-3015 GD Rotterdam, The Netherlands 